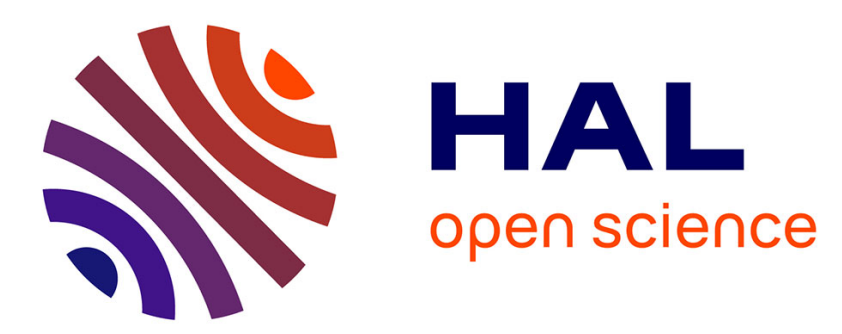

\title{
Review of Annika Herrmann, 2013. Modal and focus particles in sign languages. A cross-linguistic study (Sign Languages and Deaf Communities 2)
}

Jeremy Kuhn

\section{- To cite this version:}

Jeremy Kuhn. Review of Annika Herrmann, 2013. Modal and focus particles in sign languages. A cross-linguistic study (Sign Languages and Deaf Communities 2). 2017, pp.129-134. 10.1075/sll.20.1.05kuh. ijn_03053145

\section{HAL Id: ijn_03053145 \\ https://hal.science/ijn_03053145}

Submitted on 19 Jan 2021

HAL is a multi-disciplinary open access archive for the deposit and dissemination of scientific research documents, whether they are published or not. The documents may come from teaching and research institutions in France or abroad, or from public or private research centers.
L'archive ouverte pluridisciplinaire HAL, est destinée au dépôt et à la diffusion de documents scientifiques de niveau recherche, publiés ou non, émanant des établissements d'enseignement et de recherche français ou étrangers, des laboratoires publics ou privés. 
Review of Annika Herrmann, 2013. Modal and focus particles in sign languages. $A$ crosslinguistic study (Sign Languages and Deaf Communities 2)

Jeremy Kuhn

Institut Jean-Nicod (CNRS - EHESS - ENS), Départment d'etudes cognitives, École normale supérieure, PSL Research University

\section{Multidimensional meaning in multidimensional language}

The syntactic notion of 'particle' has been used for spoken language to encompass a large range of closed-class lexical items; syntactically, these are characterized by the fact that they never show inflection and often have flexible distributional properties. Semantically, this heterogenous class of items perform a variety of functions; while there is debate about what exactly goes in this category, these expressions include 'modal particles' (alternatively, 'discourse particles'), which express the (backgrounded) attitude of a speaker towards a proposition, and 'focus particles,' which bring semantic alternatives into the at-issue meaning of a sentence.

In the sign language modality, are these kinds of meanings expressed via the same syntactic strategies as spoken languages? Are there syntactic differences between the different classes of particles in sign language? In Modal and focus particles in sign languages, Annika Herrmann undertakes the ambitious project of answering these questions, consulting 16 signers of three different sign languages---German Sign Language (DGS), Sign Language of the Netherlands (NGT), and Irish Sign Language (ISL). Using at times both corpus data and elicitation methodologies, Herrmann examines what syntactic constructions are employed for the meanings and contexts in which particles might be used in spoken language.

To summarize the findings: across the three sign languages, there are never lexical items corresponding to modal particles in spoken languages; rather, these meanings are exclusively communicated via non-manual markers (signed with the face). This is quite a different situation from the case of focus: in all three languages, there exists a lexical translation of only and also (though even is less common). Focus constructions often (though not always) show non-manual marking on the focused constituent.

The book presents a bold undertaking---in the number of languages explored, the number of signers consulted, and the choice of empirical domain. In particular, the kinds of structures that are being explored pose a number of methodological challenges, given that they often communicate non-assertive meaning that is hard to precisely pin down. Despite these challenges, the convergence of results for both focus and modal particles speaks to the success of the strategies Herrmann employs to hone in on these meanings.

From a theoretical point of view, there are a few missed opportunities for connections and higher level discussion. Concerning modal particles, the fact that many of the same markers are used cross-linguistically is perhaps surprising, given the degree of idiosyncrasy that appears in spoken languages. Some additional speculation would be welcome regarding the difference between sign language and spoken language in this respect. Concerning focus particles, one would have liked to see more discussion of the relation between focus-sensitive operators (only, also, even) and focus marking. Across spoken languages, both of these 
phenomena are at times encoded using words that could be described as 'focus particles,' but the two serve semantically distinct functions. By focusing primarily on focus-sensitive operators, Herrmann perhaps misses generalizations about the relation of focus and nonmanual marking. Finally, the connection between the two halves of the book---modal constructions and focus constructions---is, to a large part, left surprisingly unspoken. By bringing out what these two constructions have in common, one could potentially get deeper insight into the syntax-semantics interface in the visual modality.

\section{Modal constructions}

In the first half of the book, Herrmann focuses on the kinds of meanings that in spoken language are communicated with modal particles. This class of construction is not taken to include modal verbs like must, might, need, and want, but rather, encompasses discourse particles that convey information about the knowledge or expectations of the interlocutors. In German, such particles include words like ja, schon, nur, wohl, doch, and halt which tend to be translated periphrastically in English using expressions like "as you know," and "in any case."

After corpus searches for German and Dutch particles returned inconclusive results for DGS and NGT, Herrmann adopts a paradigm in which sentences are produced by signers following establishment of a rich context that is intended to bring out a particular modal meaning. In each of DGS, NGT, and ISL, Herrmann finds that signers do not encode these meanings with lexical items, but instead use non-manual markers. Strikingly, the cross-linguistic parallels go further, with the same specific markers used for particular meanings (p. 164). For example, reference to shared or common knowledge is systematically indicated across all three languages with an eye squint; unexpectedness is systematically indicated with wide eyes. This cross-linguistic consistency is perhaps especially notable given the idiosyncrasy of grammaticalization of these meanings in spoken language; notably, English (the dominant spoken language in contact with ISL) doesn't even have clear correspondents to most the German and Dutch particles.

Herrmann does not discuss in detail what the source of this uniformity might be, but it is tempting to hypothesize that these non-manual signs are grounded at least in part in innate facial gestures. In this vein, a few controls would be informative: in particular, when hearing non-signers are presented with the same stimuli as Deaf signers, what is the rate at which they spontaneously produce (a) the relevant modal particles in spoken language and (b) the same facial expressions used by the Deaf signers? In the long run, comparing innate gestures to grammaticalized non-manual markers could in principle shed light on the cognitive underpinnings of modal meaning in language.

\section{Focus constructions}

The focus particles that Herrmann investigates are the focus-sensitive operators corresponding to English only, also, and even. Here, a corpus search for German, Dutch, and English translations performs marginally better, but generalizations are still primarily based on results to an elicitation task. At a very coarse level, Herrmann finds that there are lexical signs for only and also in each of DGS, NGT, and ISL, but finds that even is only lexicalized in ISL (and there, only marginally so). 
The typological generalizations regarding non-manual markers are not as clearly presented as those for the first part of the book, but the following generalizations seem to hold: in all languages and in all focus constructions, non-manuals and prosodic cues may be used to indicate focus marking; in particular, the focus-marked constituent is often signed with tense (manual) articulation and is often accompanied by head movements, such as head nods. Beyond the non-manuals employed to mark focus, the words for only and also themselves don't appear to be strongly associated with any additional non-manual markers. On the other hand, the meaning of even (which generally lacks a lexical translation) is frequently communicated via a cluster of non-manual markers---wide eyes and raised eyebrows. These non-manual markers may appear along with the lexical sign for also and tend to extend over an entire VP or sentence.

One thing that one would have liked to see addressed more directly is the relation between focus marking (which establishes the set of focus alternatives) and focus-sensitive operators (which take these alternatives as an argument). For instance, it bears noting that, while English primarily indicates focus marking with stress, other languages may do it through a lexical item, such as the Chinese verb shi (elsewhere a copula) that appears immediately before the focused constituent (Teng 1979). These lexical focus markers thus seem to be equally well described as 'focus particles,' but semantically perform a rather different function from words like only. This difference, as we have seen, is reflected in sign language: focus markers are encoded prosodically and non-manually; focus-sensitive operators are often lexicalized. In the case of even, where both operations may be marked non-manually, the duration of the non-manual markers is also informative; notably, when both markers occur, the non-manual corresponding with even always extends beyond the duration of the nonmanual indicating focus marking. This is exactly what we expect from a standard Roothian semantics of focus, in which focus sensitive operators take an argument with a focus-marked sub-constituent.

\section{The connection}

For the book as a whole, one of my largest questions concerns the degree to which the empirical domain---and in particular, the pairing of 'modal' and 'focus' meaning---truly forms a natural class. From the point of view of spoken language (and especially clearly from the point of German), the unification is immediately forthcoming and is syntactic; these meanings are expressed through a set of particles that have broadly similar distributional properties. Upon turning to sign languages, however, this natural class becomes somewhat more mysterious; after all, the conclusion regarding modal particles in sign languages ... is that there are none.

This is not to say the mission of unification is misguided---on the contrary, the book shows that, in sign language, non-manual markers are used to some extent for both kinds of meaning; this, too, is motivation to think of the two constructions as part of a single category of phenomena. However, as soon as the syntactic notion of particle-hood is removed from the equation, we are left with a question that Herrmann never asks directly: semantically, what is the unifying property of these meanings that induces them to be grammaticalized in similar ways across spoken languages and in similar ways across sign languages? 
I would like to suggest that the relevant property is the notion of semantic multidimensionality. Both for modality and focus, the formal semantics that has been proposed makes critical use of multiple levels of meaning. As Herrmann observes (p. 81), the kinds of 'modal' meaning discussed in this book fall into the category of conventional implicature à la Potts (2007)---non-at-issue side-computations that express additional attitudes about the asserted content. Similarly, the analysis of focus famously relies on a dimension of 'focus alternatives' (Rooth 1985) that are calculated in parallel to the main denotation. Of interest, the sign language modality also offers a multidimensional phonology, in which the face can be used simultaneously with the hands. A hypothesis: there is a linguistic pressure to employ multidimensional form to express multidimensional meaning.

Even in its imprecise formulation, this hypothesis allows us to ask a variety of new questions. For example: given the differences between the manifestation of modal and focus particles in sign language, to what extent is this predictable from the differences in semantic meaning? A possible answer: whereas the modal meanings discussed in the book are entirely non-at-issue, the focus particles discussed (particularly only and also) serve as the conduit to bring alternatives into the at-issue component of meaning; perhaps this is why the former are expressed entirely non-manually but the latter are generally lexicalized with a manual sign. On the other hand, focus marking only performs a function on the dimension of focus alternatives; we thus expect it to be indicated non-manually, which seems to indeed be the case. From this point of view, even serves a particularly interesting example, since its meaning may be expressed entirely through non-manual marking. If it turns out that the semantic contribution of 'even' non-manual marking is a non-at-issue contribution, and that its meaning is, indeed, focus-sensitive, then this provides a somewhat unique example of the interaction of two semantic dimensions, neither of which are the at-issue content.

Another question: besides the modal and focus meanings discussed by the present work, does the hypothesis of 'multidimensionality' encompass other categories of meaning? A partial answer: focus semantics involves a set of alternatives with a distinguished point (the at-issue meaning); the theory of inquisitive semantics, used to model questions and disjunction, uses similar sets of alternatives, but with no distinguished point. It is not clear whether this meets the same criteria of multidimensionality, but it bears noting that these 'inquisitive' meanings have been shown to be marked by a syntactic particle in many spoken languages (e.g., Japanese, Hungarian: Szabolcsi 2015), and that, in at least American Sign Language, raised eyebrows appear in semantically analogous constructions, including on yes/no questions and disjunction (Davidson 2013).

And finally: if there is a bias to encode these kinds of meanings using non-manual markers in sign languages, how might we expect them to be encoded in spoken languages? As Herrmann mentions, a substantial body of work has noted analogies between non-manual markers in sign language and intonational contours in spoken language. Yet, even when lexically grammaticalized in spoken language, we might speculate that constructions with a multidimensional, non-interactive semantics are also more likely to have a non-interactive syntax with fewer pressures on linearization. As it turns out, these are exactly the hallmarks of particles.

The ability to approach these questions with more than wild speculation is made possible only by the kind of careful cross-linguistic work presented by Herrmann 2013. 


\section{References}

Davidson, Kathryn. 2013. 'And' or 'or': General use coordination in ASL. Semantics \& Pragmatics 6:4. 1-44.

Herrmann, Annika. 2013. Modal and focus particles in sign languages: A cross-linguistic study. Berlin, Boston: De Gruyter Mouton.

Potts, Christopher. 2007. The expressive dimension. Theoretical Linguistics 33:2. 165-197.

Rooth, Mats. 1985. Association with focus. Amherst: University of Massachusetts dissertation.

Szabolcsi, Anna. 2015. What do quantifier particles do? Linguistics and Philosophy 38. 159-204.

Teng, Shou-hsin. 1979. Remarks on Cleft Sentences in Chinese. Journal of Chinese Linguistics 7. 101-114.

Reviewer's address

Jeremy Kuhn

Institut Jean-Nicod (CNRS)

Ecole Normale Supérieure

29, Rue d'Ulm

75005 Paris, France

jeremy.d.kuhn@gmail.com 